Article

\title{
Internet as Digital Practice: Examining Differences in African American Internet Usage
}

\section{Roderick Graham ${ }^{1}$ and Danielle Taana Smith ${ }^{2, *}$}

1 Department of Sociology, Rhode Island College, 600 Mount Pleasant Avenue, Providence, RI 02908, USA; E-Mail: rgraham@ric.edu

2 Department of Sociology and Anthropology, Rochester Institute of Technology, 18 Lomb Memorial Drive, Rochester, NY 14623, USA

* Author to whom correspondence should be addressed; E-Mail: danielle.smith@rit.edu; Tel.: +1-585-475-5133; Fax: +1-585-475-7633.

Received: 1 June 2011; in revised form: 30 June 2011 / Accepted: 8 July 2011 /

Published: 20 July 2011

\begin{abstract}
This study assesses differences within the African American population with respect to internet activity. Using survey data, we find wide variations within the population. While some segments of African Americans are indeed less likely to perform certain activities on the internet, we note that certain segments of the African American population are reporting more internet activity than other racial groups. These 'haves' score high not just in comparison to their African American peers, but to the US American population as a whole. We suggest a move away from the digital divide/digital inequality models and a move towards thinking of greater or lesser Information and Communication Technology (ICT) usage as conditioned by the instrumental needs of population groups. We term this a digital practice model.
\end{abstract}

Keywords: digital practice; digital divide; digital inequality; internet activity; African American

\section{Introduction}

Research has pointed to divergences within the African American community regarding Information and Communication Technology (ICT) use [1-3]. These divergences suggest a new trend that needs further examination. During the early internet boom of the 1990s, differences in ICT activity 
were understood using digital divide and digital inequality metaphors. Viewed as perspectives which orient research, these metaphors encapsulate the notion that there are haves and have nots in society. The haves-groups that are able to acquire and utilize ICTs such as the internet, mobile phone technology, and software applications have an advantage over the have nots, in that they are in a position to reap the benefits of ICTs, including job opportunities through social networks, key information via the internet, and the ability to conserve time and manage one's affairs using software applications. Differences in ICT usage can reinforce existing socio-economic inequalities. However, recent data suggests that emphasizing these metaphors may obfuscate important usage phenomena. Below, we discuss the digital divide and digital inequalities perspectives. Next, we discuss research on African Americans and ICT use, and argue that differences within the African American population regarding their use of technology suggest the need for a broader perspective. We then outline the basic framework for this perspective, which we term digital practice. Finally, we present data supporting the utility of the digital practice perspective.

\subsection{Digital Divide and Digital Inequality}

Generally, research on ICTs has progressed from an interest in acquisition of hardware to an interest in how hardware is being used. The understanding that some people in society had access to computers and the internet while others did not was termed the digital divide. As more people began to have access to computers, internet, and now cell phones, the focus moved to the "second digital divide" [4] or digital inequality perspective [5]. While the focus has shifted from access (digital divide) to usage (digital inequality), the basic claim that there are haves and have nots has not changed. With respect to both access and usage, studies within the United States [6-9] have consistently shown that people who are lower income, less educated, and minorities are on the wrong side of the divide.

While income and education are arguably the two most significant indicators of who is a have or have not, other factors also determine internet activity. Gender differences have been found to be significant. Willoughby (2008) found that boys in high school were significantly more likely to use the internet than their female counterparts [9]. Further, Spotts et al. (1997) report lower use of instructional technologies for women than men within a higher education faculty [10]. In computer-mediated communication technologies such as chat rooms and e-mails, the types of written content are structured by gender [11,12]. Ono and Zavodny (2003) reported that men use the internet more intensely than women, although the gap between users and non-users has disappeared [13]. Jackson et al. (2001) assert that gender differences revolved around types of usage, with women communicating online and men searching for information online [14]. Age is also a significant factor, and younger people are more frequent internet users than are older people [15-17].

In an early study of internet access and use in Switzerland between 1997 and 2000, Bonfadelli (2002) found differences in access to the internet based on education, income, age and sex. Education had the strongest effect, followed by income, with lesser effects for age and sex. These particular findings are generally similar to findings on internet access and use in the US. Bonfadelli concludes that the typical Swiss user of the internet is a well educated, affluent young male. Importantly, these gaps in access increased during the period of the study. Bonfadelli also found differences in internet usage based on educational attainment, gender and age. More highly educated people used the internet for information 
and instrumental purposes, while people with less education used the internet more for entertainment. Men were more interested in search engine features, accessing information from online papers and ebanking than were women. Compared to older people, younger people were more interested in chatting, games and music on the internet. Most importantly, Bonfadelli suggests that we lack understanding of the digital divide because research has not examined how people use the internet, and how the use of the internet is shaped by and embedded within the social construct [18].

\subsection{African Americans and Technology Usage}

The literature on differences in ICTs within African American communities is relatively sparse. This may be partly due to the aforementioned assumption that African Americans fall more or less uniformly into the have not category. From the digital divide perspective, African Americans are assumed to be homogeneous in respect to internet access and use, which is not the case. Recent research is beginning to show that this claim of homogeneity may be empirically inaccurate. Scholars have found wide variation within the African American community in personal computer ownership [19], internet usage [2], and attitudes towards technology [3]. Research indicates that not only is it misguided to uniformly categorize African Americans as a group as have nots, but it may be that they are indeed the haves in certain areas. For example, Graham (2010) found that African Americans with lower levels of educational attainment have more positive views on ICT than groups traditionally seen as more advantaged [20]. Based on data from a nationally representative survey on cell phone use in the United States conducted by the Pew Research Center, Smith (2010) suggests that minorities are more mobile than whites [21]. According to Smith:

"Continuing a trend we first identified in 2009, minority Americans lead the way when it comes to mobile access - especially mobile access using handheld devices. Nearly two-thirds of African Americans (64\%) and Latinos (63\%) are wireless internet users, and minority Americans are significantly more likely to own a cell phone than their white counterparts $(87 \%$ of blacks and Hispanics own a cell phone, compared with $80 \%$ of whites). Additionally, black and Latino cell phone owners take advantage of a much wider array of their phones' data functions compared to white cell phone owners [21]."

The literature review presents several conclusions. First, prior research using the digital divide/digital inequality perspective suggests that income, education, age, and gender effect ICT usage. Higher income, higher education, and lower ages are associated with the haves. However, gender does not have as strong an effect as it previously did. Second, prior research on African Americans and ICT usage, while relatively sparse, suggests that there are salient differences within the population. A focus on how ICTs are used, in addition to how they are accessed, could extend our understanding of the digital divide perspective and its dynamics within a particular population.

\subsection{The Digital Practice Perspective}

Exclusive focus on access to, and ownership of, technology by comparing haves and have nots, leads to the assumption that all haves use technologies similarly, and that differences in quality of connection to the internet are not significant [22]. The dichotomy between haves and have nots fails to account for the social context in which the technology is used [22]. Our analysis goes beyond the 
dichotomous distinction between haves and have nots in exploring how this distinction is manifested within a specific population previously perceived of as consisting primarily of have nots.

The majority of benefits that can be gained from ICT usage are now available to more people due to the lower economic and technical costs of entry. Scholars have identified various divides in society which hinge on resource disparities of time, money, expertise, and beliefs about technology for certain groups [23-26]. However, in technologically advanced societies, ICTs have become domesticated [27], and many benefits which accrue from ICT usage such as development of social capital and communication, do not require high levels of expertise or investment in very expensive devices. Thus, while the wealthiest segments of society can afford the fastest download speeds, this does not prevent lower income internet users from accessing the websites that are of most benefit to them. Or, while highly educated and tech-savvy users may have knowledge of the latest web applications, this will not prevent less skilled users from molding more common applications to their needs.

The notion that differences narrow as ICTs become more common seems obvious. However, we suggest that in addition to the narrowing of differences, groups previously thought of as have nots may now be considered as haves under certain measures. We suggest that as barriers such as skill and money recede, more of the variations in ICT usage will be determined by the instrumental needs of a group. Groups will use specific ICTs to accomplish specific goals. Given that population groups may face different tasks in their daily experiences, they may recruit certain aspects of ICTs to a greater or lesser extent. We term this approach which focuses on the instrumental needs of population groups as a primary determinant of ICT activity, as a digital practice perspective. With widespread access to the internet, it is now important to examine how people construct meaning and utility from their connection to the internet [22].

An initial task in developing this perspective is identifying populations within a society that exhibit unexpected levels of ICT activity on a given dimension. The digital divide and digital inequality literature review suggests that higher income, higher education, and lower ages are strongly associated with greater ICT usage. Further, gender and race/ethnicity also affect ICT usage, although these effects are not uniform. Thus, we know what to expect given a digital divide/inequality perspective, but we wish to look for those occasions when these predictors are not as effective. Our task is made more difficult since most nationally representative data do not ask questions that reveal unique practices based on instrumental group needs. In other words, questions about a respondent's work environment, family structure and daily activities are not emphasized in these studies (presumably because they are not seen as determinants of ICT activity). Thus, the conventional statistical approach of running regression models and looking for the net effects of variables that indicate digital practice versus variables that indicate digital divide/inequality is not available.

Two mechanisms are available to overcome this difficulty. First, we can examine instances where predictors work together to produce unexpected outcomes. More income and more education are associated with a greater knowledge of ICTs and more opportunities to use that knowledge. Being younger is associated with a greater acceptance of new technology and being in schools that teach technology use. However, there are population groups for whom combinations of predictors work in unexpected ways. For example, we may find that for Hispanics in rural areas, lower education is associated with an increase in ICT activity. If this is demonstrated statistically, then we can begin to explore their instrumental needs to explain why this group exhibits such unexpected usage. 
Second, we can look more closely at different types of activities, with the understanding that different activities provide different benefits for different groups. For example, we may find that young, college educated men from upper class white families may be more likely to use the internet than older Asian women from working class families. This finding would fit within a digital divide/inequality perspective. However, we could look more closely at e-commerce and find that the Asian women are more likely to buy goods online than the young men. This finding would suggest that the instrumental needs of these women are unique, so that even with the barriers associated with age and income, they find this specific activity sufficiently compelling to overcome these barriers.

Thus, although we are limited by lack of access to specific measures of instrumental needs, we can identify groups in society that exhibit unexpected ICT use. This would allow us to assume that digital practices are at work. We will look for these groups within the African American population. We choose this population because this group has been identified frequently as a have not. Instances where African Americans have disproportionately high internet activity begin to provide support for a digital practice perspective. Further, as the literature review suggests, scholars have already identified wide variation within this group. Thus, our task is to illustrate a digital practice perspective by identifying groups within the African American population who exhibit internet usage not predicted by the digital divide or digital inequality perspectives.

\section{Data and Methods}

The data for this research comes from the Pew Internet and American Life's "Spring Tracking Survey 2008". The survey was conducted between 8 April 2008 and 8 May 2008 through telephone interviews of a random sample of adults age 18 or over. The survey asks questions about respondents' internet activities and attitudes towards technology. The response rate for this survey was $25 \%$. The total number of respondents for this survey is 2251, with African American respondents numbering 215. It is worth noting that the survey may not be a fully representative survey of the US population. Pew provides a weight for this survey derived from the Census Bureau's March 2007 Annual Social and Economic Supplement to correct for response bias.

\subsection{Independent Variables}

The independent variables for the analyses that follow are: education (less than high school, high school, some college, and college graduate), income, age, student (current student, not a current student), employment status (employed full-time, employed part-time, not employed full-time or part-time), marital status (married or non-married), community status (urban, suburban, and rural), gender (male and female), race (white, black, Asian, other) and ethnicity (Hispanic, non-Hispanic). Table 1 shows the univariate statistics for independent variables. 
Table 1. Univariate statistics for independent variables.

\begin{tabular}{|c|c|c|c|}
\hline \multicolumn{5}{|c|}{ Categorical Variables } \\
\hline Variable & Freq (percentage) & Variable & Freq (percentage) \\
\hline Education & & Community Status & \\
\hline Less than High School & $198(8.9)$ & Urban & $597(26.5)$ \\
\hline High School & $718(32.3)$ & Suburban & $1142(50.7)$ \\
\hline Some College & $578(26.0)$ & Rural & $512(22.7)$ \\
\hline College Graduate & $726(32.7)$ & Gender & \\
\hline Student Status & & Male & $1024(45.5)$ \\
\hline Student & $183(8.1)$ & Female & $1227(54.5)$ \\
\hline Not Student & $2068(91.9)$ & Race/Ethnicity & $1792(81.8)$ \\
\hline Employment Status & & White H & $215(9.8)$ \\
\hline Employed full time & $952(42.3)$ & African American H & $105(4.8)$ \\
\hline Employed part time & $249(11.1)$ & Asian & $79(3.6)$ \\
\hline Not employed part or full time & $1050(46.6)$ & Other & $105(4.7)$ \\
\hline Marital Status & & Hispanic & \\
\hline Married & $1313(58.3)$ & & \\
\hline Not Married & $938(41.7)$ & Continuous Variables & \\
\hline \multicolumn{5}{|c|}{ Mean } & SD & \\
\hline Income * & 5.02 & 2.22 & \\
\hline Age & 55.1 & 19.48 & \\
\hline
\end{tabular}

* Income: $1=$ less than 10,$000 ; 2=10,000-20,000 ; 3=20,000-30,000 ; 4=30,000-40,000$; $5=40,000-50,000 ; 6=50,000-75,000 ; 7=75,000-100,000 ; 8=100,000$ and over.

\subsection{Dependent Variables}

Our main focus is on two batteries of questions. The first battery consists of several questions about general tasks done on the internet. The respondent was asked: Please tell me if you ever use the internet to do any of the following things. Do you ever use the internet to...? The second battery is more specific, and consists of questions directly related to using social networking sites on the internet. The respondent was asked: Do you ever use those [social networking] sites to...? The specific questions and the univariate statistics for each question are presented in Table 2.

Table 2. Univariate statistics for dependent variables.

\begin{tabular}{|l|c|c|c|}
\hline \multicolumn{1}{|c|}{ Basic Information Seeking } & $\underline{\text { No }}$ & $\frac{\text { Yes, Not }}{\text { Yesterday }}$ & $\begin{array}{c}\text { Yes, } \\
\text { Yesterdav }\end{array}$ \\
\hline Getting news & & & \\
\hline Checking weather reports and forecasts & 49.9 & 24.1 & 26.0 \\
\hline Look online for news or information about politics or the 2008 campaigns & 45.7 & 33.4 & 21.0 \\
\hline Visit a state, local, or government website & 54.6 & 21.8 & 15.9 \\
\hline Use an online search engine to help you find information on the Web & 38.4 & 29.5 & 8.9 \\
\hline Watch a video on a video-sharing site like YouTube or Google Video & 68.9 & 22.2 & 32.1 \\
\hline Basic Information Totals & 53.3 & 27.9 & 18.8 \\
\hline
\end{tabular}


Table 2. Cont.

\begin{tabular}{|c|c|c|c|}
\hline & $\underline{\text { No }}$ & $\frac{\text { Yes, Not }}{\text { Yesterday }}$ & $\begin{array}{c}\underline{\text { Yes, }} \\
\text { Yesterday }\end{array}$ \\
\hline \multicolumn{4}{|l|}{ Basic Information Seeking } \\
\hline \multicolumn{4}{|l|}{$\begin{array}{c}\text { Advanced Information Seeking } \\
\end{array}$} \\
\hline Send instant messages to someone who's online at the same time & 75.7 & 17.0 & 7.3 \\
\hline Create or work on your own online journal or blog & 92.7 & 4.7 & 2.7 \\
\hline Read someone else's online journal or blog & 89.2 & 7.4 & 3.4 \\
\hline Use a social networking site like MySpace, Facebook or LinkedIn.com & 85.0 & 9.0 & 6.0 \\
\hline Download a podcast so you can listen to it or view it later & 88.4 & 9.8 & 1.8 \\
\hline Watch video on a video-sharing site like YouTube or GoogleVideo & 68.9 & 22.2 & 8.9 \\
\hline $\begin{array}{l}\text { Download or share files using peer-to-peer file-sharing networks, such as } \\
\text { BitTorrent or LimeWire }\end{array}$ & 91.5 & 7.0 & 1.5 \\
\hline Advanced Information Totals & 84.5 & 11.0 & 4.5 \\
\hline \multicolumn{4}{|l|}{ Social Networking } \\
\hline & $\underline{\text { No }}$ & $\underline{\text { Yes }}$ & \\
\hline Make new friends & 93.0 & 7.0 & \\
\hline Stay in touch with friends & 87.4 & 12.6 & \\
\hline Flirt with someone & 97.2 & 2.8 & \\
\hline Make plans with your friends & 92.1 & 7.9 & \\
\hline Make new business or professional contacts & 95.9 & 4.1 & \\
\hline Promote yourself or your work & 96.0 & 4.0 & \\
\hline Organize with other people for an event, issue, or cause & 94.1 & 5.9 & \\
\hline Communication Totals & 93.7 & 6.3 & \\
\hline
\end{tabular}

\subsection{Analytic Plan}

Our research consists of two steps. First, due to the large number of total questions within the two batteries, data was reduced using factor analysis. If several factors can be extracted to represent the twenty-one total independent variables, our analysis would be simplified. Second, we wish to gain a deeper understanding of how groups within the African American population differ. We do this using Classification and Regression Tree Analysis (CART). CART analysis is a non-parametric statistical procedure that produces sub-groupings of individuals who are homogeneous with respect to a dependent variable [28]. Researchers have used CART to categorize college alumni as potential donors [29]; recidivism in a prison population [30]; the academic achievement of first generation students [31]; African Americans most likely to buy a given technology [3], and in medical research where identifying high-risk sub-groups is critical to quality treatment [32-34].

There are several advantages to using CART which make it ideal for addressing the questions posed in this study. First and foremost, CART is a classification technique that predicts a dependent variable. CART allows us to directly address our research questions. For example, consider a situation where we are interested in a scalar dependent variable. Further, we have a series of categorical independent variables (race, ethnicity, age), that we would like to use as predictors of this scale. We want to answer the question: Which groups of people score the highest (or lowest) on this scale? We are not necessarily concerned with the net effects of race, ethnicity, or age as in regression analysis. Instead, we are 
concerned with the gross effects of these variables - how they work together to influence a score on the scale. A classification tree answers this question by classifying cases according to combinations of dependent variables. CART stratifies the population with respect to this scale, and is ideal for our research. For each scale we create with factor analysis, we can develop a hierarchy of groups within the African American population. Second, because CART is a non-parametric procedure, no assumptions need to be made about the distribution of the independent variables. The data can be highly skewed or multi-modal - characteristics of the ordinal and nominal data used in this study. Third, categorical variables are handled easily in CART analysis. Differences in categorical variables in linear regression can only be assessed by creating several dummy variables. This is most effective when one or a few dummy variables are part of the analysis, and becomes less effective and more cumbersome when numerous dummies need to be created and assessed. The most important advantage of CART is that its focus is on the gross effects of variables (i.e., how they work together to produce an outcome), as opposed to net effects (i.e., the effect of one variable in predicting an outcome controlling for other variables). We present a more in-depth discussion of CART in Appendix A.

\subsection{Data Reduction}

We reduce our two batteries of questions using factor analysis with principal components extraction and varimax rotation. We run a factor analysis on each battery because these two batteries do not have the same responses. The factor analysis for the General Internet Activity battery produced two factors. One factor is composed of these activities: (1) get news; (2) check weather reports and forecasts; (3) look online for news or information about politics or the 2008 campaigns; (4) visit a state, local, or government website; (5) use an online search engine to help you find information on the Web; (6) watch a video on a video-sharing site like YouTube or Google Video. We label these six variables together as "Basic Communication Activities". These activities are characterized mainly by a one-way interaction with the internet. The user is gathering information that has already been packaged for consumption [35-37]. Basic communication activities are most likely the first activity done by novice users and require the least amount of familiarity with the internet.

The second factor is composed of these activities: (1) send instant messages to someone who is online at the same time; (2) create or work on your own online journal or blog; (3) read someone else's online journal or blog; (4) use a social networking site like MySpace, Facebook or LinkedIn.com; (5) download a podcast so that you can listen to it or view it later; (6) watch video on a video-sharing site like YouTube or GoogleVideo; (7) download or share files using peer-to-peer file-sharing networks, such as BitTorrent or LimeWire. We label this collection of activities "Advanced Communication Activities". This factor is characterized by the user taking more control of the products available on the internet. Either the user is creating new products for the internet, or the user is circumventing the predetermined channels for the standard user (using peer-to-peer file sharing networks, such as BitTorrent or LimeWire). Activity (6) (watch a video on a video-sharing site like YouTube or Google Video), is included in both the basic and advanced communications list of activities based on the results of the factor analysis.

A factor analysis was also run on the Social Networking battery of questions, but only one factor was extracted - composed of all the variables from the battery. Thus, all the questions from the social 
networking battery can be combined into one scale. Social networking is, in relation to the other two scales, the most advanced set of activities, and requires the most amount of internet knowledge. Social networking is characterized by two-way communications, and the development of content and interest based groups. In other words, social networking can lead to "virtual cliques". As in reality, these virtual cliques can monopolize information leading to disproportionate benefits for the in-group. As a consequence, this aspect of the internet has also been widely discussed [38-41]. Factor loadings are presented in Table 3.

Table 3. Rotated factor loadings for "general internet activity".

\begin{tabular}{|l|c|c|}
\hline & $\begin{array}{c}\text { Basic } \\
\text { Communication } \\
\text { Activities }\end{array}$ & $\begin{array}{c}\text { Advanced } \\
\text { Communication } \\
\text { Activities }\end{array}$ \\
\hline Getting news & 842 & \\
\hline Checking weather reports and forecasts & 819 & \\
\hline Use an online search engine to help you find information on the Web & 812 & \\
\hline Visit a state, local, or government website & 770 & \\
\hline Look online for news or information about politics or the 2008 campaigns & 748 & \\
\hline look online for information about a job & & \\
\hline make a donation to a charity & & 673 \\
\hline Use a social networking site like MySpace, Facebook or LinkedIn.com & & \\
\hline Create or work on your own online journal or blog & & 574 \\
\hline $\begin{array}{l}\text { Download or share files using peer-to-peer file-sharing networks, such as } \\
\text { BitTorrent or LimeWire }\end{array}$ & & 573 \\
\hline Send instant messages to someone who's online at the same time & & 561 \\
\hline Watch a video on a video-sharing site like YouTube or Google Video & 511 & 518 \\
\hline $\begin{array}{l}\text { Download a podcast so you can listen to it or view it later } \\
\text { Read someone else's online journal or blog }\end{array}$ & \\
\hline - Extraction Method: Principal Component Analysis; \\
Rotation Method: Varimax with Kaiser Normalization; \\
Rotation converged in 3 iterations.
\end{tabular}

In sum, we have three dependent variables-"Basic Communication Activities", "Advanced Communication Activities", and "Social Networking". We conducted a reliability analysis on the variables that compose each factor. If the variables are sufficiently correlated (as evidenced by an alpha of over .700), then we can combine the variables that load onto each factor into a more understandable scale. The alpha for "Basic Communication Activities" was .893; it was .763 for "Advanced Communication Activities", and it was .869 for "Social Networking". These high alphas suggest that we can create three scales. We interpret these scales such that higher scores mean that a respondent or group is doing more internet activities within this specific domain. It would be safe to argue that there is an increase in complexity from basic communication to advanced communication. For social networking, however, the claim instead is that higher scores represent a more intense usage of one aspect of the internet. These scales can provide rough measures of disproportionate benefits accrued through the internet. A respondent who scores a 1 on social networking can be said to have participated in social networking via the internet. However, a person who scores a 4 on the same scale 
is doing more total networking activities. The mean for basic communication activities is 4.28 (range $0-12$ ), with a standard deviation of 3.7. The mean for advanced communication activities is 1.78 (range $0-14$ ) with a standard deviation of 2.44 . The mean for the networking scale is 0.7 (range $0-7$ ) with a standard deviation of 1.52 .

\section{Results and Discussion}

A CART analysis was conducted on all three internet activity scales, stratifying the African American population with respect to each scale. We have also completed CART analyses for non-African American respondents and included the highest and lowest strata for these groups. These provide a comparison for the African American groups. We discuss each model in kind.

\subsection{Basic Communication}

Basic communication (Table 4) is the set of activities with the lowest barriers to entry. Thus the "breaks"- the points at which CART divides the population into more or less homogenous groups - are relatively inclusive. In general, the group that has the most frequent basic communication activity, group 1, is composed of African Americans 42 years of age or younger with greater than a high school diploma. This represents one-quarter of the population. If we compare this have within the African American population with the have of the rest of the population, we see that the most advantaged African Americans tend to fare less well against the most advantaged of other groups. The mean for group 1 in the African American population is 4.59, while the mean is 6.80 for others. Further, this top group for others is more inclusive than the African American top group, as it includes everyone under the age of 52 or less with a high school diploma. Finally, and most generally, the mean for all African Americans on this measure is lower than for other groups (3.28 to 4.40). Based on the activities that compose basic communication, African Americans are relatively disadvantaged.

Table 4. CART analysis for basic communication.

\begin{tabular}{|c|c|c|c|c|c|}
\hline \multirow[b]{2}{*}{ Group \# } & \multicolumn{4}{|l|}{$\begin{array}{l}\text { African Americans } \\
\quad \text { Mean }=3.28\end{array}$} & \multirow{2}{*}{\begin{tabular}{|c|}
$\begin{array}{c}\text { Other Respondents } \\
\text { Mean }=\mathbf{4 . 4 0}\end{array}$ \\
\end{tabular}} \\
\hline & Group Description & $N$ & Percent & Mean & \\
\hline 1 & $\begin{array}{c}\text { Age } \leq 42 \text { years old } \\
\text { Education }>\text { High school }\end{array}$ & 178 & $23.3 \%$ & 6.29 & \multirow{2}{*}{$\begin{array}{c}\text { Educ }>\text { High School } \\
\text { Age } \leq 52 \\
\text { Pct. }=33 \% \\
\text { Mean }=6.80\end{array}$} \\
\hline 2 & $\begin{array}{c}\text { Age } \leq 42 \text { years old } \\
\text { Education } \leq \text { High school } \\
\text { Employment status }=\text { Employed part time or full time }\end{array}$ & 128 & $16.7 \%$ & 4.84 & \\
\hline 3 & $\begin{array}{c}\text { Age }>42 \text { years old } \\
\text { Education }>\text { High school }\end{array}$ & 131 & $17.1 \%$ & 3.69 & \\
\hline 4 & $\begin{array}{c}\text { Age }>42 \text { years old } \\
\text { Education }>\text { High school } \\
\text { Income }>\$ 40,000\end{array}$ & 103 & $13.5 \%$ & 1.69 & \\
\hline
\end{tabular}


Table 4. Cont.

\begin{tabular}{|c|c|c|c|c|c|}
\hline 5 & $\begin{array}{c}\text { Age } \leq 42 \text { years old } \\
\text { Education } \leq \text { High school } \\
\text { Employment status }=\text { Not employed part time or full } \\
\text { time }\end{array}$ & 55 & $7.2 \%$ & 1.67 & $\begin{array}{c}\text { Educ } \leq \text { High School } \\
\text { Age }>70 \\
\text { Pct. }=9.7 \\
\text { Mean }=.5117\end{array}$ \\
\hline 6 & $\begin{array}{c}\text { Age }>42 \text { years old } \\
\text { Education }>\text { High school } \\
\text { Income } \leq \$ 40,000\end{array}$ & 170 & $22.2 \%$ & .141 & \\
\hline
\end{tabular}

\subsection{Advanced Communication}

The picture begins to increase in complexity with the CART analysis for advanced communication (Table 5). Although the overall mean for African Americans is lower than that of other racial groups, there are some haves in the African American population who outstrip the haves for other groups. Distinguishing features of these haves are their age and marital status. The African American group aged 22 and younger, which is at the top of the advanced communication hierarchy, has a mean of 4.49, compared with a mean of 2.88 for the top other group. In this case, African Americans are haves. Also, respondents who are relatively young, between 23 and 39 years old, and married or living with a partner also score higher than the top other group. It should be noted that compared to other ethnoracial groups, there is a greater amount of exclusivity within the African American population. Groups 1 and 2 combine for about one-quarter of the population, while the top group for other ethnoracial categories is composed of $47 \%$ of the population.

Table 5. CART analysis for advanced communication.

\begin{tabular}{|c|c|c|c|c|c|}
\hline & \multicolumn{4}{|l|}{$\begin{array}{l}\text { African Americans } \\
\quad \text { Mean }=1.69\end{array}$} & \multirow[t]{2}{*}{$\begin{array}{c}\text { Other Respondents } \\
\text { Mean }=1.80\end{array}$} \\
\hline Group \# & Group & $\underline{N}$ & Percent & Mean & \\
\hline 1 & Age $\leq 22$ & 94 & $12.3 \%$ & 4.59 & \multirow{2}{*}{$\begin{array}{c}\text { Age } \leq 46 \\
\text { Pct. }=46.8 \\
\text { Mean }=2.88\end{array}$} \\
\hline 2 & $\begin{array}{c}\text { Age }=\text { between } 23 \text { and } 39 \\
\text { Marital Status }=\text { Married or Living with Partner }\end{array}$ & 85 & $11.1 \%$ & 3.52 & \\
\hline 3 & $\begin{array}{c}\text { Age }>40 \\
\text { Education }>\text { High School Diploma } \\
\text { Marital Status }=\text { Married or Living with Partner }\end{array}$ & 58 & $7.6 \%$ & 2.38 & \\
\hline 4 & $\begin{array}{l}\text { Age }=\text { between } 22 \text { and } 40 \\
\text { Marital Status }=\text { Not Married or Living with Partner }\end{array}$ & 124 & $16.2 \%$ & 2.35 & \\
\hline 5 & $\begin{array}{c}\text { Age }>40 \\
\text { Education }>\text { High School Diploma } \\
\text { Marital Status }=\text { Not Married or Living with Partner }\end{array}$ & 99 & $12.9 \%$ & 1.00 & \multirow{2}{*}{$\begin{array}{c}\text { Age }>46 \\
\text { Education }<=\text { High School } \\
\text { Pct. }=27.3 \\
\text { Mean }=.37\end{array}$} \\
\hline 6 & $\begin{array}{c}\text { Age }>40 \\
\text { Education } \leq \text { High School Diploma or Less }\end{array}$ & 305 & $39.9 \%$ & .10 & \\
\hline
\end{tabular}




\subsection{Social Networking}

The final measure of internet activity focuses solely on social networking activities (Table 6). There is an increase in complexity from basic communication to advanced communication. For social networking, however, the claim instead is that higher scores represent a more intense usage of one aspect of the internet. With this in mind, we can say that overall African Americans are greater social networkers than other ethnoracial groups (group mean of 0.86 as opposed to 0.65 ). The factors that lead to greater social networking for African Americans are age $(\leq 32)$ and income $(\leq \$ 30,000)$. For group 2 in the social networking hierarchy, employment matters, with those who are not employed being relatively high social networkers. Paradoxically, these respondents in group 2 do report an income while being unemployed. A possible explanation for this would be that income represents family income and these respondents may be married or have a partner who is employed. Regardless of how this discrepancy for Group 2 is explained, we can still assert that African Americans are greater social networkers.

Table 6. CART analysis for social networking.

\begin{tabular}{|c|c|c|c|c|c|}
\hline & \multicolumn{2}{|c|}{$\begin{array}{c}\text { African Americans } \\
\text { Mean }=\mathbf{0 . 8 6}\end{array}$} & \multicolumn{2}{|c|}{$\begin{array}{c}\text { Other Respondents } \\
\text { Mean }=\mathbf{0 . 6 5}\end{array}$} \\
\hline Group \# & Group & 126 & $16.5 \%$ & 3.24 & $\begin{array}{c}\text { Age } \leq 26 \\
\text { Pct. }=12.5 \% \\
\text { Mean }=2.48\end{array}$ \\
\hline 1 & $\begin{array}{c}\text { Age } \leq 32 \\
\text { Income } \leq \$ 30,000\end{array}$ & 56 & $7.3 \%$ & 2.25 & \\
\hline 2 & $\begin{array}{c}\text { Age } \leq 32 \\
\text { Income }>\$ 30,000\end{array}$ & 72 & $9.4 \%$ & .944 & \\
\hline 3 & $\begin{array}{c}\text { Age } \leq 32 \\
\text { Income }>\$ 30,000\end{array}$ & 511 & $66.8 \%$ & .114 & $\begin{array}{c}\text { Pct. }=24.7 \% \\
\text { Mean }=.051\end{array}$ \\
\hline 4 & Employment Status $=$ Not employed full time & & & \\
& Age $>32$ & & & & \\
\hline
\end{tabular}

\section{Conclusions}

\subsection{Support for a Digital Practice Perspective}

The purpose of this study was to illustrate a digital practice perspective by identifying groups within the African American population which exhibit internet usage not predicted by the digital divide or digital inequality perspectives. To this end, we developed three distinct measures of internet activity, and looked for differences between African Americans and other racial groups, and for differences within the African American population. Within the African American population, we observe wide variation. While some segments of the population are indeed less likely to perform certain activities on the internet, we observe that other segments of the African American population are reporting more 
internet activity than other racial groups. These groups score high not just in comparison to their African American peers, but to the population as a whole. We can present the findings of the three CART analyses as such:

(1) On average, African Americans use the internet for basic communication activities relatively less frequently than do other ethnoracial groups;

(2) On average, African Americans as a group use the internet for advanced communication activities relatively less frequently than other ethnoracial groups. However, distinct groups within the population - those 22 and under and those who are married - score extremely high on this scale;

(3) On average, African Americans are greater social networkers than other ethnoracial groups. Further, these social networkers are younger and have lower incomes.

The findings suggest that while African Americans are often disadvantaged, there are certain activities in which some groups within this population could be considered advantaged. These groups are (1) young adults under the age of 22 who use the internet for advanced communication activities; (2) those who are married who use the internet for advanced communication activities; and (3) low income, young adults under the age of 32 who use the internet for social networking. Advantages among African Americans cannot be explained using traditional predictors of haves and have nots. We suggest that these advantaged groups have specific instrumental needs that allow them to overcome some of the barriers to ICT activity. These findings support a digital practice framework for ICT usage.

While the focus of this paper was on African Americans, the delineation of homogenous groupings also revealed the continuing significance of age. Younger people consistently perform more ICT activities than do older people. Our findings suggest that age works differently for the African American population. The age break separating the advantaged from the disadvantaged appears to be lower for African Americans. However, age is a factor for all activities and for all groups. A generational divide is evident in all the analyses, but a more detailed analysis of the effect of age is beyond the scope of this paper. Further analyses of age divisions both between and within racial and ethnic groups would further understanding of the digital practice perspective, which we suggest for future studies.

Past conclusions about African American ICT usage were made from the digital divide/inequality perspectives which focused on population disadvantage. African Americans have been clearly disadvantaged regarding access to and use of ICTs, however, assumptions regarding causes of disadvantage have remained unchallenged. There has not been sufficient data to examine in greater detail how African Americans use ICTs. Further conceptualizations are needed to explore relationships between individuals and technology and to contextualize these relationships based on broader societal conditions [22]. Conclusions from our study may apply to other racial and ethnic groups. However, each group has significant within group differences, and should be investigated based on the unique needs of groups within the population. Generalizations about population groups should be minimized in order to also minimize flawed assumptions about these groups that directly influence policy making. Diverse factors and relationships among these factors affect populations differently, partially based on the instrumental needs of groups within the population. Further studies are needed to better elucidate the diverse factors which affect technology use within diverse population groups. 


\subsection{Future Directions}

As societies continue to domesticate ICTs, they become everyday objects in our lives [42] and are subject to the particular instrumental needs of population groups. The traditional barriers to ICT usage that were hallmarks of the digital divide and digital inequality paradigms — income and education — are giving way to barriers that are more subjective and context-specific. This understanding explains the importance of other factors in classifying populations. We noted that marital status was associated with greater levels of advanced communication, and that not being employed was associated with an increase in social networking. We can assume that these particular groups of African Americans are using ICTs because they help them accomplish particular goals in their lives. Our research is not the only one of its type to take a social constructivist angle, and illustrate how groups in various social contexts have used ICT for their own group specific needs [43-46], typically using quantitative methods. However, our goal was to delineate these groups statistically, at a macro level so as to make claims about the structure of ICT activity at a societal level.

There are more nuanced societal divisions, and social divides may also be the result of digital practice divides based on the needs of particular groups. Mobile phone usage may be predicated on the number and intensity of social networks. The use of a new social network site may be more determined by how the site is marketed and less on the amount of technological skill one possesses. The adoption of an e-reader may be due more to living in an urban environment where public transportation leads to increased commuting times than to any inherent predilection for new gadgets. We suggest a move away from the digital divide/digital inequality models and a move towards thinking of greater or lesser ICT usage as conditioned by the instrumental needs of population groups. This does not mean that traditional indicators of inequality such as age, income, education, and race are no longer relevant. Indeed, our current findings suggest that age is still a significant variable, and that any study using a digital practice perspective may find it useful to explore instrumental needs associated with age and technology.

Employing a digital practice perspective provides new insight as to how to mitigate inequalities. Recognizing that internet activity is powered by instrumental needs suggests that the links between education, income and internet usage in general are important but may explain progressively less as societies increasingly rely on technologies. Scholars may need to rethink how inequalities are addressed. Specifically, when access is an issue, the more money one makes the easier it is to pay for online service. The response to the disparity in access is to place computers and internet services in schools or in community centers where low income people live. When usage is the focus, the more internet savvy someone is, the more benefits they can extract from their time online. The response to this disparity is to provide computer and internet classes. However, if internet activity is powered by instrumental needs, the imposition from above of technology and computer education classes may be misdirected. As the example of African American males who surpass other groups in networking activity indicates, groups lacking in education and income will figure out the internet if there is enough incentive and opportunity to use it. From a digital practice perspective, the response to disparities in internet activity is to focus on altering what is offered by the internet and other forms of technology, and not on the socio-demographic characteristics of the users. 


\section{References}

1. Chakraborty, J.; Bosman, M.M. Measuring the digital divide in the United States: Race, income, and personal computers. Prof. Geogr. 2005, 57, 395-410.

2. Lenhart, A.; Horrigan, J.; Rainie, L.; Allen, K.; Boyce, A.; Madden, M.; O’Grady, E. The evershifting internet population: A new look at internet access and the digital divide. The Pew Internet \& American Life Project 2003. Available online: http://www.pewinternet.org/pdfs/PIP_Shifting Net_Pop_Report.pdf (accessed on 1 December 2010).

3. Graham, R.; Smith, D.T. Dividing lines: An empirical examination of technology use and internet activity among African Americans. Inf. Commun. Soc. 2010, 13, 892-908.

4. Attewell, P. The first and second digital divides. Sociol. Educ. 2001, 74, 252-259.

5. Dimaggio, P.; Hargittai, E.; Celeste, C.; Shafer, S. Digital Inequality: From Unequal Access to Differentiated Use. In Social Inequality; Nekerman, K., Ed.; Russell Sage Foundation: New York, NY, USA, 2004; pp. 355-400.

6. National Telecommunications and Information Administration. A Nation Online: Entering the Broadband Age; U.S. Department of Commerce: Washington, DC, USA, 2004.

7. Hargittai, E. Survey measures of web-oriented digital literacy. Soc. Sci. Comput. Rev. 2005, 23, 371-379.

8. Hargittai, E. The Role of Expertise in Navigating Links of Influence. In The Hyperlinked Society; Turow, J., Tsui, L., Eds.; The University of Michigan Press: Ann Arbor, MI, USA, 2008; pp. 85-104.

9. Willoughby, T. A short-term longitudinal study of internet and computer game use by adolescent boys and girls: Prevalence, frequency of use, and psychosocial predictors. Dev. Psychol. 2008, 44, 195-204.

10. Spotts, T.H.; Bowman, M.A.; Mertz, C. Gender and use of instructional technologies. High. Educ. 1997, 34, 421-426.

11. Gefen, D.; Straub, D.W. Gender differences in the perception and use of e-mail: An extension to the technology acceptance model. MIS Q. 1997, 21, 389-400.

12. Koch, S.C.; Meuller, B.; Kruse, L.; Zumbach, J. Constructing gender in chat groups. Sex Roles 2005, 53, 29-41.

13. Ono, H.; Zavodny, M. Immigrants, English ability, and the digital divide. Soc. Sci. Q. 2008, 36, 1135-1155.

14. Jackson, L.; Ervin, K.; Gardner, P.; Schmitt, N. Gender and the Internet: Women communicating and men searching - statistical data included. Sex Roles 2001, 44, 363-380.

15. Bimber, B. Measuring the gender gap on the internet. Soc. Sci. Q. 2000, 81, 868-876.

16. Lorence, D.P.; Heeyoung, P. New technology and old habits: The role of age as a technology chasm. Technol. Health Care 2006, 14, 91-96.

17. Xie, B.; Jaeger, P. Older adults and political participation on the internet: A cross-cultural comparison of the USA and China. J. Cross-Cult. Gerontol. 2008, 23, 1-15.

18. Bonfadelli, H. The internet and knowledge gaps: A theoretical and empirical investigation. Eur. $J$. Commun. 2002, 17, 65-84. 
19. Chakraborty, J.; Bosman, M.M. Measuring the digital divide in the United States: Race, Income, and Personal Computers. Prof. Geogr. 2005, 57, 395-410.

20. Graham, R. ICT as cultural practice: Group differences in attitudes towards technology among Americans. New Media Soc. 2010, 12, 985-1003.

21. Smith, A. Mobile Access. Pew Internet and American Life Project. 2010. Available online: http://www.pewinternet.org/Reports/2010/Mobile-Access-2010.aspx (accessed on 1 December 2010).

22. Jung, J.; Qui, J.L.; Kim, Y. Internet connectedness and inequality: Beyond the "Divide". Commun. Res. 2001, 28, 507-535.

23. Norris, P. Digital Divide: Civic Engagement, Information Poverty and the Internet Worldwide; Cambridge University Press: Cambridge, MA, USA, 2001.

24. Mossberger, K.; Tolbert, C.J.; Gilbert, M. Race, place, and information technology. Urban Aff. Rev. 2006, 41, 583-620.

25. Van Dijk, J.A. The Deepening Divide: Inequality in the Information Society; Sage Publications: London, UK, 2005.

26. Wilson, E.J. The Information Revolution and Developing Countries; MIT Press: Cambridge, MA, USA, 2004.

27. Haddon, L. The contribution of domestication research to in-home computing and media consumption. Inf. Soc. 2006, 22, 195-203.

28. Brieman, L.; Friedman, J.; Stone, C.J.; Olshen, R.A. Classification and Regression Tree Analysis; CRC Press: Boca Raton, FL, USA, 1984.

29. Weerts, D.J.; Ronca, J.M. Using classification trees to predict alumni giving for higher education. Educ. Econ. 2009, 17, 95-122.

30. Stalans, L.J.; Yarnold, P.R.; Seng, M.; Olson, D.E.; Repp, M. Identifying three types of violent offenders and predicting violent recidivism while on probation: A classification tree analysis. Law Hum. Behav. 2004, 28, 253-271.

31. Grayson, J.P. Academic achievement of first-generation students in a Canadian university. Res. High. Educ. 1997, 38, 659-676.

32. Pawloski, L.R.; Kitsantas, P. Classification tree analysis of stunting in Malian adolescent girls. Am. J. Hum. Biol. 2008, 20, 285-291.

33. Kershaw, T.S.; Lewis, J.; Westdahl, C.; Wang, Y.F.; Rising, S.S.; Massey, Z.; Ickovics, J. Using clinical classification trees to identify individuals at risk of STDs during pregnancy. Perspect. Sex. Reprod. Health 2007, 39, 141-148.

34. Hartling, L.; Pickett, W.; Brison, R.J. Derivation of a clinical decision rule for whiplash associated disorders among individuals involved in rear-end collisions. Accid. Anal. Prev. 2002, 34, 531-539.

35. Cothey, V. A longitudinal study of world wide web users' information-searching behavior. J. Am. Soc. Inf. Sci. Technol. 2002, 53, 67-78.

36. Rieh, S.Y. On the web at home: Information seeking and web searching in the home environment. J. Am. Soc. Inf. Sci. Technol. 2004, 55, 743-753. 
37. Hargittai, E. Hurdles to information seeking: Spelling and typographical mistakes during users' online behavior. J. Assoc. Inf. Syst. 2006, 6, 1-25.

38. Brunsting, S.; Postmes, T. Social movement participation in the digital age: Predicting offline and online collective action. Small Group Res. 2002, 33, 525-554.

39. Warschauer, M. Technology and Social Inclusion: Rethinking the Digital Divide; MIT Press: Cambridge, MA, USA, 2003.

40. Adams, J.; Roscgino, V.J. White supremacists, oppositional culture and the world wide web. Soc. Forces 2005, 84, 759-778.

41. Garofalo, R.; Herrick, A.; Mustanski, B.S.; Donenberg, G.R. Tip of the iceberg: Young men who have sex with men, the internet, and HIV risk. Am. J. Public Health 2007, 97, 1113-1117.

42. Baym, N. Personal Connections in the Digital Age; Polity Press: Cambridge, MA, USA, 2010.

43. Mehra, B.; Merkel, C.; Peterson, B.A. The internet for empowerment of minority and marginalized users. New Media Soc. 2004, 6, 781-802.

44. Campbell-Grossman, C.K.; Hudson, D.B.; Keating-Lefler, R.; Heusinkvelt, S. New mothers network: The provision of social support to single, low-income, African American mothers via e-mail messages. J. Family Nurs. 2009, 15, 220-236.

45. Crang, M.; Crosbie, T.; Graham, S. Variable geometries of connection: Urban digital divides and the uses of information technology. Urban Stud. 2006, 43, 2551-2570.

46. Stern, M.J.; Adams, A. Do rural residents really use the internet to build social capital? An empirical investigation. Am. Behav. Sci. 2010, 53, 1389-1422.

\section{Appendix}

CART analysis uses independent variables provided by the researcher to produce sub-groupings of individuals who are homogeneous with respect to a dependent variable. CART analysis is a form of binary recursive partitioning. The term "binary" implies that each collection of cases can only be split into two sub-groups, called child nodes. Because the process is "recursive", the partitioning process is applied over and over again. Each parent node can produce two child nodes and, in turn, each of these child nodes may themselves be split. The term "partitioning" refers to the fact that the dataset is split into homogenous sub-groups. Strictly speaking, a classification tree involves the prediction of a dichotomous variable, while a regression tree involves the prediction of an ordinal variable.

The first step in CART analysis consists of partitioning the entire dataset into binary subsets on the basis of a selected variable split. Initially, all cases are clustered into one "parent node". This initial node has a certain level of heterogeneity, or impurity with respect to the dependent variable. This impurity can be considered a statistic that measures the degree to which cases differ on values of the dependent variable. The calculation for impurity in any given population is:

$$
D=\sum_{i=1}^{S} p_{i}^{2} \text {. }
$$

In this equation, $\mathrm{p}_{\mathrm{i}}$ is the proportion of cases in the population which have a certain value. Each proportion is squared, and then all squared proportions are summed. The rationale behind splitting is to 
reduce the impurity of a parent node by selecting the one variable that is most effective in dividing the original population into less heterogeneous sub-groups.

The most common statistical technique used for determining a reduction of impurity, and the one used in this research, is the Gini improvement measure. To calculate improvement, first the impurity of the original node is calculated. A variable is selected and used to split this original parent node into child nodes. For example, if the variable is race, all respondents who identified themselves as "Asians" would be lumped together, and all non-Asians are lumped together. Next, the impurities for these new child nodes are calculated in the same manner. Then, a weighted average of the Gini diversity index is computed according to the proportion of the parent node included in each of the child nodes:

Weighted Gini diversity index $=\left[\left(p_{1}\right)\left(\right.\right.$ impurity $\left.\left._{1}\right)\right]+\left[\left(p_{2}\right)\left(\right.\right.$ impurity $\left.\left._{2}\right)\right]$

Finally, a Gini improvement measure is calculated:

Improvement measure $=$ impurity of parent node - weighted Gini diversity index

The independent variable which produces the largest improvement measure is retained as the splitting variable. This process then repeats itself for each of the two child nodes (which now have become parent nodes). In this way, impurity is steadily reduced, leading to more homogeneous sub-groupings.

Trees can grow to large sizes. Large trees present more splits and more homogenous sub-groups, however a large tree has terminal nodes that are too numerous to be theoretically interesting or the $\mathrm{N}$ of these nodes are so small that these nodes are not capturing reproducible phenomena. In other words, a tree that has grown to its maximal size predicts the data perfectly, but is likely capturing idiosyncrasies in the data instead of generalizable patterns. Thus, the second step in CART analysis is stopping the splitting process and producing a tree that balances accuracy with parsimony. One way of controlling size is by assigning stopping rules. These rules define the minimum number of respondents per parent node, child node, and the maximum levels of the tree. The default option in SPSS is 100 for parent nodes, 50 for child nodes, and a maximum depth of 5 levels. Further, the minimum amount of improvement in impurity needed for a predictor variable to split a population can be modified. Higher minimum levels of improvement mean that fewer splits will occur. This creates a simpler tree, but nodes are relatively more heterogeneous. Conversely, decreasing the minimum amount of improvement creates more homogeneous groupings, and a more accurate tree overall, but the tree could be too large or too complex to derive any general patterns. Modifying stopping rules or minimum improvement values do not change the development of the tree, but only limits the complexity of the tree. A second mechanism for controlling the size of a tree is pruning. CART prunes by first growing a tree to its maximal size, and then reducing the size of the tree by removing branches that do not add to the overall prediction rate of the tree.

The next step is judging overall quality. The overall structure of the tree is judged through a splitsample technique. A small test sample is randomly selected from the overall sample and submitted to an independent CART analysis. This test sample is used to validate the results of the original sample. Similar splits and nodes for the training sample and test sample show support for reliable results. Finally, results are interpreted. As in other types of analyses, there are many ways of interpreting data. A logical first step is to focus on the terminal nodes, the nodes that are "childless". A tree is interpreted 
by assessing the means of the terminal nodes and the splitting logic that led to these terminal nodes. Means for each terminal node with respect to the dependent variable are presented in the output. By assessing the splitting logic, profiles of the individuals that make up homogenous groups with respect to the dependent variable can be created.

(C) 2011 by the authors; licensee MDPI, Basel, Switzerland. This article is an open access article distributed under the terms and conditions of the Creative Commons Attribution license (http://creativecommons.org/licenses/by/3.0/). 